Rhode Island College

Digital Commons @ RIC

\title{
Effects of Workplace Violence on Nurses Working in the Emergency Department
}

Alicia Blythe

Follow this and additional works at: https://digitalcommons.ric.edu/etd

Part of the Other Nursing Commons

\section{Recommended Citation}

Blythe, Alicia, "Effects of Workplace Violence on Nurses Working in the Emergency Department" (2018).

Master's Theses, Dissertations, Graduate Research and Major Papers Overview. 260.

https://digitalcommons.ric.edu/etd/260

This Major Paper is brought to you for free and open access by the Master's Theses, Dissertations, Graduate Research and Major Papers at Digital Commons @ RIC. It has been accepted for inclusion in Master's Theses, Dissertations, Graduate Research and Major Papers Overview by an authorized administrator of Digital Commons @ RIC. For more information, please contact digitalcommons@ric.edu. 


\title{
EFFECTS OF WORKPLACE VIOLENCE ON NURSES WORKING IN THE EMERGENCY DEPARTMENT
}

\author{
by
}

\author{
Alicia Blythe \\ A Major Paper Submitted in Partial Fulfillment \\ of the Requirements for the Degree of \\ Master of Science in Nursing \\ in \\ The School of Nursing \\ Rhode Island College \\ 2018
}




\begin{abstract}
Workplace violence has been a trending topic of discussion across the country and is a concern for employees nationwide. The Emergency Department has been consistently documented as one area where workplace violence is most prevalent and presents a greater risk for occupational hazard. The escalating acts of violence toward emergency department nurses across the country have drastically increased and nurses have become targets of verbal and emotional abuse, subjected to threatening behavior, and have become victims of physical assaults. The purpose of this project was to identify the effects of workplace violence on nurses working in the Emergency Department. A quantitative descriptive study using modified Emergency Nurses Association (ENA) Workplace Violence staff assessment survey was used to identify emergency department nurses' experiences with workplace violence. The mixed method design included a descriptive survey as well as series of open-ended questions to elicit personal accounts of violence in the workplace. A total of 36 nurses in the Emergency Department at Newport Hospital, a 129 bed community hospital in Newport, RI were surveyed. The results of the survey identified $95.45 \%(n=21)$ of nurses have experience some form of workplace violence. Physical violence such as being hit, punched, slapped, kicked, pinched, pushed, shoved, and scratched was experienced by at least half of nurses. Additionally, documented effects of workplace violence on staff members included burnout, low department morale, physical and emotional distress, and contributed to overall job dissatisfaction. The study identified workplace violence as an issue and recognizes the effects of violence on staff members is of significant concern that should be addressed with leadership support to recognize and decrease workplace violence in the ED.
\end{abstract}





\section{Acknowledgements}

I dedicate this to my mother and sister for their endless love and support. To my mother, your illness has deprived you from some of the most formative years of my life however it has also guided me into a profession that I love which has been influential to the person that I am today and for that I am grateful. 


\section{Table of Contents}

Background/Statement of the Problem .............................................................. 1

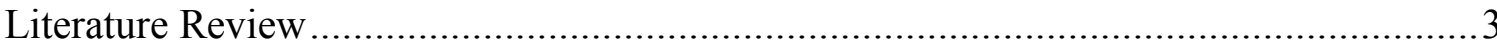

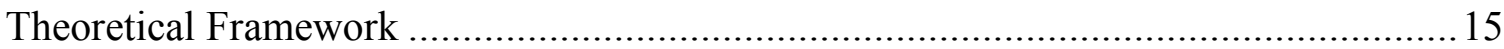

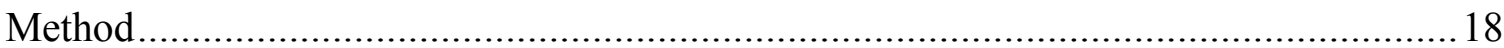

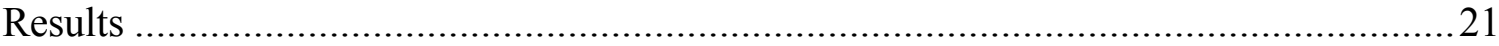

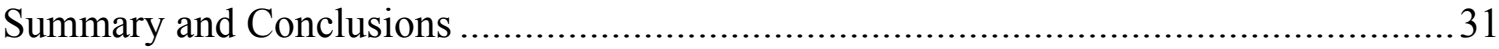

Recommendations and Implications for Advanced Nursing Practice........................... 35

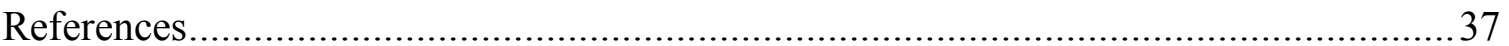

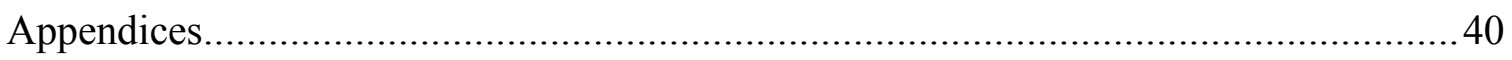


Effects of Workplace Violence on Nurses Working in the Emergency Department

\section{Background/Statement of the Problem}

The prevalence of work place violence (WPV) is an increasing matter of concern for many people in the professional work force on a national scale. In 2013, the Bureau of Labor Statistics reported more than 23,000 significant injuries are due to assaults at work and more than 70 percent of these assaults were in healthcare and social service settings (OSHA National News Release, 2015, para 1). The act of violence within the workplace is not discriminatory, can be displayed in multiple forms, and effects numerous occupations. Occupational Safety and Health Administration (OSHA) defines workplace violence as any act or threat of physical violence, harassment, intimidation, or other threatening disruptive behavior that occurs at the work site and can range from threats, verbal abuse, physical assaults or even homicide and can involve employees, clients, customers and visitors (Workplace Violence, Para 2).

Nationally the escalating incidence of workplace violence is affecting healthcare workers from various disciplines and places healthcare workers at a greater risk for harm. Within the healthcare setting, the Emergency Department has been consistently documented as one area where workplace violence is most prevalent and presents a greater risk for occupational hazard. More specifically, escalating acts of violence toward emergency department nurses across the country have drastically increased and nurses have become targets of verbal and emotional abuse, subjected to threatening behavior, and have become victims of physical assaults. Over $70 \%$ of emergency department nurses reported physical or verbal assault by patients or visitors while providing patient care in the emergency setting (Wolf, Delao, \& Perhats, 2014). These 
acts of violence have been associated with physical safety concerns, job dissatisfaction, and ultimately have impact emotional well-being.

The purpose of this project is to identify the effects of workplace violence on nurses working in the Emergency Department.

Next, a review of the relevant literature will be presented. 


\section{Literature Review}

A search of the literature from 2000-2017 was performed using Cumulative Index to Nursing and Allied Health Literature (CINHAL) and PubMed using the search terms 'workplace violence', 'emergency department' 'safety' 'nurses' 'assault' 'violence against nurses' 'violence in healthcare' 'nurse's safety'.

\section{Workplace Violence Defined}

According to the National Institute for Occupational Safety and Health (NIOSH), workplace violence (WPV) is the act or threat of violence, ranging from verbal abuse to physical assaults directed toward persons at work or on duty (Occupational Violence, 2016). The impact of workplace violence can range from psychological abuse to physical injury, or even death (Center for Disease Control, 2016). The term has been further defined through a collaborative effort of the International Labor Office (ILO), International Council of Nurses (ICN), World Health Organization (WHO), and Public Service International (PSI) which further delineates workplace violence as incidents where staff are abused, threatened or assaulted in circumstances related to their work, including commuting to and from work, involving an explicit or implicit challenge to their safety, well-being or health (DiMartino, 2002). Workplace violence is generally defined as any physical assault, emotional or verbal abuse, or threatening, harassing, or coercive behavior in the work setting that causes physical or emotional harm (Wolf et al., 2014). These descriptions provide a common definition that workplace violence is behaviors of verbal, physical, or emotional abuse toward staff that results in concern for personal safety. 


\section{Workplace Violence in Healthcare}

Violence in the healthcare setting, from patients or visitors, in the form of verbal, physical, and/or emotional violence has steadily been on the rise and has emerged as a prominent matter within the healthcare industry globally. A study performed by Hahn, et. al., (2012) examined the occurrence of patient and visitor violence (PVV) toward healthcare staff (HCS), interventions performed, and consequences related to violence. A cross sectional survey provided a questionnaire to 4845 staff members in a Swiss general hospital who had direct contact with patient and families between MayJuly 2007. The survey was distributed only to medical units with specialty areas and did not contain any psychiatric units. The study sample consisted of nurses, midwives, medical doctors, physical therapists, occupational therapist, dieticians, ward secretaries, medical assistants, radiology assistants, nursing assistants, and laboratory workers. In total, 2495 workers completed and returned the questionnaires (51.5\%), a majority of respondents were women with (82\%), half were between the ages of 30-45 years old and overall $(52 \%)$ of participants were full time employees, and only $(16.4 \%)$ were trained in aggression management. Within the year preceding the collection of this data $(50.2 \%)$ of the HCS experienced PVV, verbal abuse was (45.9\%), physical abuse (16.9\%), and threats $(16.9 \%)$. Exposure to violence varied among occupations with nurses and midwives being identified as most exposed at (56.6\%). Within the hospital the exposure to PVV varied among different units with highest violence occurring within emergency room $(73.9 \%)$, recovery rooms, anesthesia, intermediate care and step-down units (59.4\%), intensive care (58.8\%), and outpatient areas (57.2\%). Hahn et al., (2012) the findings confirm existing evidence that HCS in general hospitals experience high levels 
of PVV, in particular verbal violence. The consequences of workplace violence were also discussed, acknowledging the significant emotional impact on those staff members involved. Hahn et al., (2012) identified the emotional impact of PVV was upsetting for $90 \%$ of HCS who experienced verbal violence and over $(60 \%)$ for those who experience physical violence. Several HCS reported suffering from serious consequences and had to take sick leave. The survey indicated that training and aggression management classes did not influence the level of confidence in dealing with violence and the absence of organizational policies and procedures concerning violence negatively influenced the level of confidence of HCS (Hahn, et al., 2012).

In a study by Arnetz et al, (2015) patient to worker violence was explored through a qualitative analysis of documented reports of violence in the year 2011 by employees of an American hospital system which consisted of seven hospitals with 15,000 employees with centralized reporting system. A sample of 214 incidents were reviewed and majority of the incidents were reported by nurses (39.8\%), security staff (15.9\%), and nurse's assistants (14.4\%). Approximately $90 \%$ of the 214 incidents reported included some form of physical assault which resulted in injuries (34\%) requiring time away from work (Arnetz, et al., 2015). The findings of the study identified three themes that were prominent prior to the reported episode of patient violence toward staff: patient behavior, patient care, and situational events. Patient behavior accounted for $40 \%$ of the reported incidents of violence and was further categorized into two addition themes related to cognitive impairment and demanding to leave. The sub-theme of cognitive impairment included those patients with dementia, agitation, confusion, intoxication related to alcohol or drugs and children. Incidents that fell under the cognitive impairment and 
demanding to leave sub-themes indicated the patient characteristics were the direct catalyst for incidents (Arnetz, et al., 2015). 'Demanding to leave' included a population of patients who were attempting to elope from the hospital prior to being formally discharged. The "patient care" theme reflected those patients who became violent with staff members when they were involved in a treatment that entailed pain, discomfort, or physical transfer. Several of these incidents cited resulted in potentially serious employee injuries, including needle sticks and human bites (Arnetz, et al., 2015). Situation events that were examined encompassed significant changes in patient care such as during transfer of care between units, restraining patients, restricting or redirecting patients for safety of the patient or staff. Arnetz, et al., (2015) states healthcare and security staff were injured some of them seriously, by violent patient behavior during this type of incident and staff need to be aware of increased risk for violence in transitioning situations.

\section{Workplace Violence and Nursing}

Acts of workplace violence have become an increasing concern for various occupations however nursing is identified as one occupation where there is an increased incidence of violence. Physical violence against nurses has become an endemic problem affecting nurse in all settings (Gillespie, Gates, \& Berry, 2013).

A study performed by Gerberich, et al. (2005) investigated the rate of exposure to workplace violence for registered nurses (RN) and licensed practical nurses (LPN) in the state of Minnesota. With approval of the University of Minnesota Institutional Review Board, 6300 licensed RNs and LPNs who worked in Minnesota for at least 12 months prior to completing the survey were contacted using a mailed questionnaire. The 
questionnaire asked respondents to provide demographic information, physical and nonphysical work related violent events, and the number of months the nurse has worked in their current nursing position in the previous 12 months. Of the 6,300 RN/LPNs that were contacted 1,900 RN/LPNs in the state of Minnesota responded. Of those that responded, 475 nurses acknowledged one or more episodes of physical violence within the previous twelve-months (Gerberich, et al., 2005). Of the questionnaires returned, $96 \%$ of the respondents were female, the average age was 46 years old, $75 \%$ were RNs and remaining were LPNs. The results from this study indicated a significant correlation with work environment and those at increased risk for violence within the workplace. Gerberich, et al. (2005), found an increased risk of work related physical assaults among nurses who worked in nursing homes or long-term care facilities as well as those working in psychiatric and emergency departments.

On an international scale the prevalence of workplace violence in nursing is also of concern. Zhang, Wang, Xie, Zhou, Li,..., Zhang, (2017) conducted a large study including 4,125 nurses randomly selected from 28 hospitals in China from seven geographical regions. A descriptive cross-sectional study gathered information from nurses related to the prevalence of workplace violence, practice environment, and empathy levels utilizing the Workplace Violence Incident Survey, the Jefferson Scale of Empathy Health Professionals (JSE-HP), and the Practice Environment Scale of Nursing Work Index (PES-NWI). Of those that responded 92.7\% ( $\mathrm{n}=3835)$ were between the ages of $18-57$ years and had worked as a nurse for 7.98 years. Regarding the prevalence of workplace violence against Chinese nurses, the authors reported verbal abuse was most commonly experienced at (61.25\%), followed by threats (36.75\%), physical 
violence (25.90\%), and sexual harassment (2.76\%) (Zhang, et al., 2017). Some of the recognized risk factors discussed was the association between previous experience with violence and potential for repeat exposure, rotating schedule, department where nurses work, level of empathy, and poor working environments. The fact that reports of violence dropped with length of service for all types of violence suggests that novice nurses were more vulnerable to experiencing workplace violence in comparison to experienced nurses (Zhang, 2017). Additionally, the study found an association between rotating schedules and those that are at increased risk for violence, recognizing a relationship between senior and novice nurses and identified novice nurses that do not work fixed shifts were at an increased risk for violence. Furthermore, nurses in Chinese hospitals have a strong sense of hierarchy, the probability of a young nurse working a rotating roster was much higher than that of an older nurse (Zhang, 2017). Empathy for care was also identified as a risk factor for violence, recognizing the importance of compassion in nursing care. The Jefferson Scale of Empathy- Health Professionals (JSEHP) was utilized within the survey which consists of a 7-point Likert scale which included three themes: perspective taking, compassionate care, and standing in the patient's shoes. This tool was used to measure healthcare worker' empathy toward patients noting the higher the score the greater the empathy. As stated in (Zhang, 2017), nurses with low levels of perspective taking had 1.5 times the odds of suffering physical violence compared to nurses with high levels of perspective taking and similar odds were identified for compassion for care and standing in the patients' shoes. Finally, the nursing environment was identified as having significant impact on risk for physical and non-physical violence in the workplace. The Practice Environment Scale of the Nursing 
Work Index (PES-NWI) instrument was used as a measurement for nursing work environment where "positive" work environment has a higher score. Among the subscales of the PES-NWI, lower scores on the staffing, resource adequacy, and foundations for quality care subscales were associated with non-physical violence, whereas lower scores for nurses participating in hospital affairs and collegial nursephysician relationships were associated with physical violence (Zhang, et al., 2017).

Nurses with low levels of perspective taking had 1.4 times the odds of suffering physical violence compared to nurses with high levels of perspective taking. The nursing profession in China has been identified an inferior profession to that of a physician, placing nurses at a lower social status in eyes of the patients. Zhang (2017) states patients are likely to first express their anger to nurses rather than to doctors when they object to treatment process or results, even if they are dissatisfied with the doctors. Nurses become scape goats for the doctors, which, to some extent, increases the risk of being the target of violence.

\section{Effects of Workplace Violence on Emergency Department Nurses}

A quantitative study by Erikson \& William-Evan (2000), recruited a sample of 55 emergency department nurses from two hospitals in the mid-southern region of the United States and surveyed them on the frequency of assaults and their attitudes about patient assaults through a thirty-one-item questionnaire. This study reported that $82 \%$ of the nurses surveyed experienced being physically assaulted by patients during their career (Erikson \&William-Evan, 2000). Fifty-six percent had been assaulted within the preceding year and $29 \%$ of those assaults were unreported (Erikson \& Williams-Evans, 2000). The study acknowledged a significant correlation between the frequency of 
assaults and reporting of those assaults, identifying a trend that the more prior assaults nurses have had experienced, the less likely they were to report it. The authors concluded that patient assaults may become 'part of the job' and overtime, may no longer even be recognized as assaults (Erikson \& Williams-Evans, 2000). In addition, the authors found that the nurses often reported feeling unsafe in the emergency department setting. Seventy-three percent of nurses agreed with the statement, "Nurses can expect to be physically assaulted at some time during their careers' and 76\% stated their ED accepted patients that they were not staffed or equipped to handle. Only $2 \%$ of nurses felt safe 'all of the time' while at work, $34 \%$ felt safe 'most of the time', $15 \%$ felt safe 'some of the time', and $4 \%$ felt safe 'none of the time' (Erikson \& Williams-Evans, 2000).

A study by Catlette (2005) included a phone interview with eight registered nurses from two different Level I Trauma Centers regarding their experience with workplace violence. Participants were recruited on site at change of shift, instructed to email their willingness to participate and then later contacted by phone by the author for a scheduled interview. An interview guide was used with a series of open ended questions regarding workplace violence. The interviews identified two themes: inadequate safety measures and vulnerability. A primary point of concern reported by nurses was how easily people from the outside the hospital could gain access with their weapons to the emergency department, and how the responsibility of the surveillance placed a burden on the already busy nursing staff (Catlette, 2005). In addition, nurses discussed situations at work that created the feeling of being vulnerable to the occurrence of violent incidents. Most of the nurses stated that they feel unsafe at work and that safety improvements were needed in the emergency departments where they worked (Catlette, 2005). 
Gacki-Smith, Juarez, \& Boyett (2009) described emergency nurses’ experiences and perceptions of violence from patients and visitors in US emergency departments through a cross sectional study. A 69-item online survey was given to emergency room nurses who were members of the Emergency Nurses Association (ENA) and working in US emergency departments. As many as 3,465 nurses completed the survey. The study was a one-time online survey, accessible to members of the ENA for one month through ENA solicitation via email, newsletter, and website. Some of the most common types of physical violence experienced by more than $50 \%$ of respondents were 'spit on' 'hit,' 'pushed/shoved,' 'scratched,' and 'kicked.' In terms of verbal abuse, $70 \%$ or more of respondents experienced being "yelled/cursed at," "intimidated," and "harassed with sexual language and/innuendo." Sixty-seven percent rated their perception of safety at a 5 or below on a 10-point scale and one third had considered leaving their ED or emergency nursing because of ED violence (Gacki-Smith, Juarez, \& Boyett, 2009).

Similarly, in an article by Wolf et al. (2014) a qualitative descriptive design was used to identify emergency department nurse's experiences of violence while providing care. This study consisted of forty-six written narratives from emergency department nurses who were recruited by email from the membership roster of the Emergency Nurses Association (ENA) and through solicitation of members on the ENA website. A total of 46 written narratives from nurses were returned that addressed the question "Tell me about your experience of violence in the emergency setting." Of the responses, eight were identified as men, 37 women, and one nurse of an unknown gender. The results of the study identified three themes of environment, personal, and cue recognition. The environmental theme addressed issues such as unsafe conditions within the emergency 
department and identified categories such as 'culture of acceptance'; 'unsafe workplace', and 'nobody cares', 'nothing changes.' Participants described unsafe work environments, where safety measures were put into place, for example security cameras or panic buttons, but were not maintained or enforced (Wolf et al., 2014). A few participants reported having been assaulted more than once and were frustrated by the lack of real change in security or environmental protective measures (Wolf et al., 2014). The personal theme identified by Wolf et al. (2014) included lingering trauma; permanent injury and loss; denial of impact; and changes in job responsibilities, hours, or location. Respondents describe lingering psychological trauma that continued to impede their ability to work in the emergency setting (Wolf et al., 2014). The personal accounts of their experience with workplace violence identified fear of returning to work, difficulties working within certain sections of the department where they are secluded from the rest of the staff, hesitancy when dealing with violence situations, and personal accounts of post-traumatic stress. Additionally, some nurses discussed the concept of 'denial of impact' on a personal scale or from coworkers and elaborated that the perception of violence within the emergency department is expected and considered part of the job. Cue recognition or precursors to potential violence were often overlooked or not identified, and the healthcare facility's ability to recognize high risk patients was unreliable. A notable category around cue recognition was "without provocation" in which nurses detailed clear cues of threats yet appeared completely taken by surprise at the violent attack or verbal outburst by the patient (Wolf et al., 2014). In addition, there were specific situations in which nurses have identified patients at high risk for violence related to their medical and physical presentation who were not perceived to pose an 
imminent risk, however experienced an acute unprovoked escalation in behavior and became physically violent with staff. Furthermore, Wolfe et al. (2014) reported accounts of patients who were reported to be physically violent and or restrained by emergency medical staff or police officers prior to presentation to the ED, however first responders failed to appropriately identify these patients as high risk for violence at hand off. A frequent scenario was the lack of institutional recognition of the high-risk patient, leaving the nurse in a vulnerable position without resources or recourse (Wolf et al., 2014).

\section{Education and Management of Workplace Violence}

According to the Occupational Safety and Health Administration (2016), workplace violence warrants further education and training for nurses. A universal program aimed at prevention of workplace violence has not been adopted on a national scale. Education is crucial to provide nurses and staff members with safety strategies to properly identify and handle violence within the workplace with the intention of averting adverse staff outcomes. Ray (2007), recommends that nurses should be a part of prevention, planning, monitoring, risk assessment, development of workplace safety policies, and implementation of security measures.

Within certain healthcare organizations, training programs for staff are implemented to provide them with nonviolent crisis intervention techniques when dealing with potential situations that could result in violence. Lifespan has adopted and utilized a consulting firm that provides a training program for all of its employees through Crisis Prevention Institute (CPI) which does just that. CPI provides employees with safe, respectful, noninvasive methods for managing disruptive and assaultive behaviors in a 
way that is compatible with staff's duty to provide the best possible care (Crisis Prevention Institute, 2017).

Despite efforts to address workplace violence in various health care settings it remains a significant concern for healthcare workers. Specifically, emergency department nurses state that they are particularly vulnerable to violence within their workplace. Considering the continued threat that ED nurses report and the multiple and heterogeneous interventions implemented by healthcare settings in recent years, further investigation exploring the current experience of workplace violence on emergency department nurses is warranted

Next, the theoretical framework guiding this project will be presented. 


\section{Theoretical Framework}

Adapting to the environment, situation, and individual patient are ways in which emergency department nurses are able to combat circumstances involving work place violence. Taylor's theory of cognitive adaptation recognizes that frequently those that experience personal tragedy or set-backs often don't seek professional help and will utilize individual resources and social networks to overcome personal difficulties. Taylor (1983) despite serious setbacks such as personal illness or the death of a family member, the majority of people facing such blows achieve a quality of life or level of happiness equivalent to or even exceeding their prior level of satisfaction and furthermore they do so substantially on their own. The theory suggests that one must participate in the process of adjustment in order for one to overcome a threatening event and return to a quality of life that is an acceptable level prior to the threatening experience. The three themes within this theory include searching for meaning in the experience, an attempt to regain mastery over the event in particular and over one's life, and an effort to restore one's self esteem.

Finding the meaning of the event is directed at identifying and understanding why the threatening event occurred and the impact of the event on those involved. Specifically, meaning is an effort to understand the event: why it happened and what impact it has had. The search for meaning attempts to answer the question, what is the significance of the event? (Taylor, 1983).

The second theme addresses one's ability to regain control over the situation and recognize the influence it has on one's life. This theme was specific to the managing of the threatening event and prevention of a similar event from reoccurring. Accordingly, a 
second theme of the adjustment process is gaining a feeling of control over the threatening event, manage it or keep it from occurring again (Taylor, 1983).

Threatening events can have significant impact on one's self-esteem, the third theme identified is the need for self-improvement and rebuild self-esteem. Taylor (1983) states even when the events can be legitimately attributed to external factors beyond the individual's control, there is often a precipitous drop in self-esteem. After experiencing such a drop, however, many individuals then initiate cognitive efforts to pull themselves back out of their low self-regard and find ways to feel good about oneself again.

Violent events in the emergency department can have a significant impact on nurses. The theory of cognitive adaptation can be useful in guiding and assist in overcoming experiences of violence within the emergency department and provide the ability of nurses to adapt to threatening behavior. Being able to identify the three themes discussed, nurses can work though experiences and search for meaning which will allow them to review the incident and identify why it happened. Regaining mastery over the event will allow them to identify ways in which things could have been addressed differently or recognize how the violent incident could have been prevented.

Lastly the ability to adapt to a violence event by enhancing one's self esteem is the most crucial. The experience of workplace violence can have a significant impact on Emergency Department nurses' personal and professional confidence. Adjusting to the violence event provides the ability for nurses to restore their personal and or professional confidence to the prior level before the event. The theory maintains that when individuals experience personal tragedies or setbacks, they respond with cognitively 
adaptive efforts that may enable them to return to or exceed their previous level of psychological functioning (Taylor, 1983). The theory of cognitive adaptation and the three themes it encompasses will guide the project.

Next, the methodology for the project will be presented. 
Purpose

\section{Method}

The purpose of this project was to identify the effects of workplace violence on nurses working in the Emergency Department.

\section{Design}

A quantitative descriptive study using modified ENA Workplace Violence staff assessment survey was used to identify emergency department nurses' experiences with workplace violence. The mixed method design included a descriptive survey as well as series of open ended questions to elicit personal accounts of violence in the workplace.

\section{Sample}

A convenience sample was used for this project. Inclusion criteria was all registered nurses, full time, part time and per diem currently working in the Emergency Department at Newport Hospital. Exclusion criteria included any management staff and newly hired staff nurses within the past 12 months currently in orientation to the ED.

Site

The site for the survey was Newport Hospital, a 129-bed community hospital in Newport, RI. Lifespan Newport Hospital Emergency Department sees annually 31,000 patients in the 17 bed ED.

\section{Procedures}

Letter of approval was obtained from the Newport Hospital Emergency Department Director (Appendix A) and Chief Nursing Officer (Appendix B). The ENA workplace violence survey was adapted for this project. The project was submitted to 
and approved by the Institutional Review Board (IRB) at Newport Hospital and Rhode Island College.

An informational email was sent to staff and notified them of the purpose of the survey, the time-line of the project and included a link to the online survey to complete (Appendix C) if they chose to participate. Staff had two weeks to participate in the survey after the email was sent.

\section{Measurement}

The measurement tool was a modified version of the Emergency Nurses Association (ENA) 16-item survey on workplace violence with two additional openended questions (Appendix D). The tool was originally developed by the ENA and is part of their violence toolkit and is already reviewed for validity, and is available on the Emergency Nurses Association (ENA) website for public use (Emergency Nurses Association, 2010). Modifications were made to the original tool to exclude any questions that were not relevant to the topic being studied and the facility where the study was performed. Additional open-ended questions were included that solicit nurses personal experience of violence within the workplace. The tool was peer reviewed by an ED nurse educator for survey content and structure.

\section{Data Analysis}

Descriptive statistical analysis was used to identify the quantity and types of violence being experienced by ED nurses and identify the effects of violence on nurses. Descriptive statistical analysis was used to identify themes related to workplace violence in the emergency department elicited through nurse's response to open ended questions on workplace violence. The data is displayed in a graph format. 


\section{Dissemination Plan}

The results of this project was shared with the $\mathrm{CNO}$ and Director of the Emergency Department at Newport Hospital and Emergency Department staff at the monthly unit council meeting. The project will be presented at the Rhode Island College Master Project presentations in May 2018.

Next, the results will be presented. 


\section{Results}

The purpose of this project was to identify the effects of workplace violence on nurses working in the Emergency Department at Newport Hospital. Of the 36 eligible staff nurse, 22 completed the survey for overall response rate of $61.1 \%$. The gender analysis for the study included 3 males $(13.04 \%)$ and 19 females $(86.36 \%)$. Of the 22 respondents $50 \%(n=11)$ had 10 years or more of professional nursing experience. The distribution of shifts included days $40.91 \%(n=9)$, evenings $36.36 \%(n=8)$, and nights $22.73 \%(n=5)$. Employment status of those that participated included fulltime $63.64 \%$ $(n=14)$, part-time $13.64 \%(n=3)$, and per diem $22.73 \%(n=5)$. The frequency of personal experience with workplace violence over the past year included 2 or less $31.82 \%(n=7)$, 3-5 times $31.82 \% 9(n=7), 6-8$ times $4.55 \%(n=9),>10$ times $31.82 \%(n=7)$. Figure 1 on the follow page exhibits the frequency of assaults on participants within the past year. 
Figure 1. Frequency of Assaults on Staff Members Over the Past Year

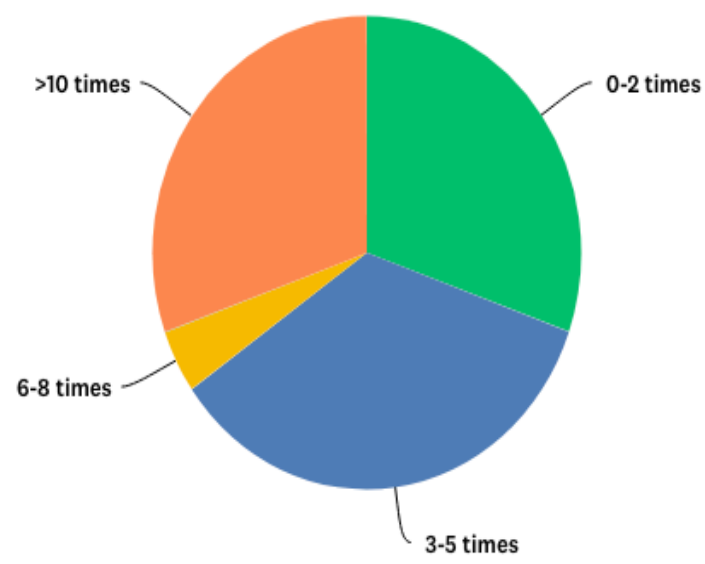

ANSWER CHOICES

- 0-2 times

- 3-5 times

- 6-8 times

- 9-10 times

- >10 times

TOTAL
- RESPONSES

$30.43 \%$

$34.78 \%$

$4.35 \%$

$0.00 \%$

$30.43 \%$
8 0 
The survey consisted of a modified version of the ENA workplace violence survey that consisted of a 20 item checklist of behaviors (Emergency Nurses Association, 2010). Participants were asked to identify if each behavior listed constituted workplace violence and whether it was experienced by the respondent and an additional category of other was also included to allow staff to provide staff opportunity to include any act that wasn't mentioned. On the follow page Table 1 demonstrates participant's responses to the listed violent behaviors. 
Table 1

Percentage of Staff That Considered the Action to Be Example of Workplace Violence

\begin{tabular}{|c|c|c|c|}
\hline $\boldsymbol{\nabla}$ & YES THIS IS WORKPLACE VIOLENCE & NO THIS IS NOT WORKPLACE VIOLENCE & $\begin{array}{l}\text { TOTAL } \\
\text { RESPONDENTS }\end{array}$ \\
\hline Bitten & $\begin{array}{r}100.00 \% \\
22\end{array}$ & $\begin{array}{r}0.00 \% \\
0\end{array}$ & 22 \\
\hline Called Names & $\begin{array}{r}90.91 \% \\
20\end{array}$ & $\begin{array}{r}9.09 \% \\
2\end{array}$ & 22 \\
\hline Hair pulled & $\begin{array}{r}100.00 \% \\
22\end{array}$ & $\begin{array}{r}0.00 \% \\
0\end{array}$ & 22 \\
\hline $\begin{array}{l}\text { Harassed with } \\
\text { sexual } \\
\text { language/innuendo }\end{array}$ & $\begin{array}{r}95.45 \% \\
21\end{array}$ & $\begin{array}{r}4.55 \% \\
1\end{array}$ & 22 \\
\hline $\begin{array}{l}\text { Hit (e.g., punched, } \\
\text { slapped) }\end{array}$ & $\begin{array}{r}100.00 \% \\
22\end{array}$ & $\begin{array}{r}0.00 \% \\
0\end{array}$ & 22 \\
\hline $\begin{array}{l}\text { Hit by thrown } \\
\text { objects }\end{array}$ & $\begin{array}{r}100.00 \% \\
22\end{array}$ & $\begin{array}{r}0.00 \% \\
0\end{array}$ & 22 \\
\hline Kicked & $\begin{array}{r}100.00 \% \\
22\end{array}$ & $\begin{array}{r}0.00 \% \\
0\end{array}$ & 22 \\
\hline Other & $\begin{array}{r}100.00 \% \\
2\end{array}$ & $\begin{array}{r}0.00 \% \\
0\end{array}$ & 2 \\
\hline - Pinched & $\begin{array}{r}100.00 \% \\
22\end{array}$ & $\begin{array}{r}0.00 \% \\
0\end{array}$ & 22 \\
\hline - Pushed/Shoved & $\begin{array}{r}100.00 \% \\
22\end{array}$ & $\begin{array}{r}0.00 \% \\
0\end{array}$ & 22 \\
\hline Scratched & $\begin{array}{r}100.00 \% \\
22\end{array}$ & $\begin{array}{r}0.00 \% \\
0\end{array}$ & 22 \\
\hline Sexually assaulted & $\begin{array}{r}95.45 \% \\
21\end{array}$ & $\begin{array}{r}4.55 \% \\
1\end{array}$ & 22 \\
\hline - Shot/Shot at & $\begin{array}{r}95.45 \% \\
21\end{array}$ & $\begin{array}{r}4.55 \% \\
1\end{array}$ & 22 \\
\hline Spit on/at & $\begin{array}{r}100.00 \% \\
22\end{array}$ & $\begin{array}{r}0.00 \% \\
0\end{array}$ & 22 \\
\hline Stabbed & $\begin{array}{r}95.45 \% \\
21\end{array}$ & $\begin{array}{r}4.55 \% \\
1\end{array}$ & 22 \\
\hline - Sworn/cursed at & $\begin{array}{r}95.45 \% \\
21\end{array}$ & $\begin{array}{r}4.55 \% \\
1\end{array}$ & 22 \\
\hline $\begin{array}{l}\text { Threatened with } \\
\text { physical harm }\end{array}$ & $\begin{array}{r}100.00 \% \\
22\end{array}$ & $\begin{array}{r}0.00 \% \\
0\end{array}$ & 22 \\
\hline $\begin{array}{l}\text { Verbally } \\
\text { intimidated }\end{array}$ & $\begin{array}{r}100.00 \% \\
22\end{array}$ & $\begin{array}{r}0.00 \% \\
0\end{array}$ & 22 \\
\hline Void on/at & $\begin{array}{r}86.36 \% \\
19\end{array}$ & $\begin{array}{r}13.64 \% \\
3\end{array}$ & 22 \\
\hline - Yelled/Shouted at & $\begin{array}{r}95.45 \% \\
21\end{array}$ & $\begin{array}{r}4.55 \% \\
1\end{array}$ & 22 \\
\hline
\end{tabular}


Review of results, it was found that a majority of the participants identified that most of the behaviors listed constituted workplace violence. More specifically acts such as being bitten, hair pulled, being hit by thrown object, kicked, pinched, pushed/shoved, scratched, spit on/at, threatened with physical harm and being verbally intimated were identified as acts of workplace violence by $100 \%$ of the staff $(n=22)$. Interestingly $13.64 \% \%(n=3)$ of the staff did not classify the act of being intentionally voided on or voided as an act of workplace violence. Additionally, the category of other was acknowledged by $100 \%(n=2)$ which listed additional actions they identified as act of workplace violence such as being threatened and intimidated by family members and having a colostomy bag removed and thrown at a staff member.

Next Table 2 will demonstrate the percentage of staff that has experienced workplace violence. 
Table 2

Percentage of Staff That Has Experienced Workplace Violence

\begin{tabular}{|c|c|c|c|}
\hline$\checkmark$ & I HAVE EXPERIENCED & I HAVE NOT EXPERIENCED & $\begin{array}{l}\text { TOTAL } \\
\text { RESPONDENTS }\end{array}$ \\
\hline Bitten & $\begin{array}{r}31.82 \% \\
7\end{array}$ & $\begin{array}{r}68.18 \% \\
15\end{array}$ & 22 \\
\hline Called Names & $\begin{array}{r}95.45 \% \\
27\end{array}$ & $\begin{array}{r}4.55 \% \\
1\end{array}$ & 22 \\
\hline Hair pulled & $\begin{array}{r}27.27 \% \\
6\end{array}$ & $\begin{array}{r}72.73 \% \\
16\end{array}$ & 22 \\
\hline $\begin{array}{l}\text { Harassed with } \\
\text { sexual } \\
\text { language/innuendo }\end{array}$ & $\begin{array}{r}72.73 \% \\
16\end{array}$ & $\begin{array}{r}27.27 \% \\
6\end{array}$ & 22 \\
\hline $\begin{array}{l}\text { Hit (e.g., punched, } \\
\text { slapped) }\end{array}$ & $\begin{array}{r}77.27 \% \\
17\end{array}$ & $\begin{array}{r}22.73 \% \\
5\end{array}$ & 22 \\
\hline $\begin{array}{l}\text { Hit by thrown } \\
\text { objects }\end{array}$ & $\begin{array}{r}50.00 \% \\
11\end{array}$ & $\begin{array}{r}50.00 \% \\
11\end{array}$ & 22 \\
\hline Kicked & $\begin{array}{r}68.18 \% \\
15\end{array}$ & $\begin{array}{r}31.82 \% \\
7\end{array}$ & 22 \\
\hline Other & $\begin{array}{r}100.00 \% \\
2\end{array}$ & $\begin{array}{r}0.00 \% \\
0\end{array}$ & 2 \\
\hline Pinched & $\begin{array}{r}59.09 \% \\
13\end{array}$ & $\begin{array}{r}40.91 \% \\
9\end{array}$ & 22 \\
\hline - Pushed/Shoved & $\begin{array}{r}54.55 \% \\
12\end{array}$ & $\begin{array}{r}45.45 \% \\
10\end{array}$ & 22 \\
\hline - Scratched & $\begin{array}{r}59.09 \% \\
13\end{array}$ & $\begin{array}{r}40.91 \% \\
9\end{array}$ & 22 \\
\hline Sexually assaulted & $\begin{array}{r}0.00 \% \\
0\end{array}$ & $\begin{array}{r}100.00 \% \\
22\end{array}$ & 22 \\
\hline - Shot/Shot at & $\begin{array}{r}9.09 \% \\
2\end{array}$ & $\begin{array}{r}90.91 \% \\
20\end{array}$ & 22 \\
\hline Spit on/at & $\begin{array}{r}72.73 \% \\
16\end{array}$ & $\begin{array}{r}27.27 \% \\
6\end{array}$ & 22 \\
\hline Stabbed & $\begin{array}{r}0.00 \% \\
0\end{array}$ & $\begin{array}{r}100.00 \% \\
22\end{array}$ & 22 \\
\hline - Sworn/cursed at & $\begin{array}{r}90.91 \% \\
20\end{array}$ & $\begin{array}{r}9.09 \% \\
2\end{array}$ & 22 \\
\hline $\begin{array}{l}\text { Threatened with } \\
\text { physical harm }\end{array}$ & $\begin{array}{r}77.27 \% \\
17\end{array}$ & $\begin{array}{r}22.73 \% \\
5\end{array}$ & 22 \\
\hline $\begin{array}{l}\text { Verbally } \\
\text { intimidated }\end{array}$ & $\begin{array}{r}95.45 \% \\
21\end{array}$ & $\begin{array}{r}4.55 \% \\
1\end{array}$ & 22 \\
\hline - Void on/at & $\begin{array}{r}27.27 \% \\
6\end{array}$ & $\begin{array}{r}72.73 \% \\
16\end{array}$ & 22 \\
\hline - Yelled/Shouted at & $\begin{array}{r}95.45 \% \\
21\end{array}$ & $\begin{array}{r}4.55 \% \\
1\end{array}$ & 22 \\
\hline
\end{tabular}


Review of Table 2 illustrates that an overwhelming majority of the staff have experience some form of workplace violence. Specifically, 95.45\% (n=21) have experience some form of non-physical violence such as being called names, being verbally intimidated, and being yelled/shouted at. Table 2 depicts acts of physical violence such as being hit, punched, slapped, kicked, pinched, pushed, shoved, and scratched as experienced by at least half of the participants. Interestingly it was reported by $9.09 \%(n=2)$ that they have experienced being shot or shot at. 
All the participants that completed the survey, the responses to the question "is workplace violence part of the job" was well divided among all 22 individuals. Those that answered yes were $59.09 \%(n=13)$ and those that answered no accounted for $40.91 \%$ $(n=9)$. Figure 1 illustrates these results.

Figure .2 Percentage of Staff That Identified Workplace Violence as Part of the Job

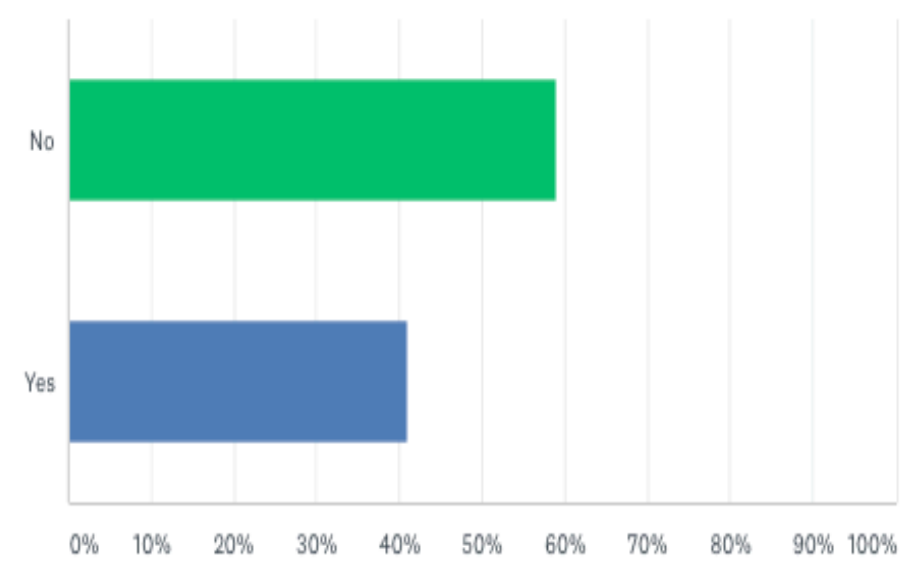

\begin{tabular}{llr} 
ANSWER CHOICES & RESPONSES & - \\
- NO & $59.09 \%$ & 13 \\
\hline Y YeS & $40.91 \%$ & 9 \\
TOTAL & & 22
\end{tabular}


Next, the open-ended questions were reviewed, the first question asked the participants to include how workplace violence has affected them. Overall, 18 out of the 22 respondents answered this open-ended question. From these responses seven themes were identified which included burnout, consumes resources, department morale, emotional/physical stress, increasingly cautious, and job dissatisfaction. It was reported by one respondent that they did not experience workplace violence $5.56 \%(n=1)$. Overall burnout $27.78 \%(n=5)$, emotional/physical stress $27.78 \%(n=5)$, and being increasingly cautious with patients $27.78 \%(n=5)$ were the most discussed. In some cases, more than one theme was identified by the same participant so the graph depicts more responses than the original sample participants. Figure 2 displays the identified effects of workplace violence.

Figure 3. Themes Identified With the Effects of Workplace Violence on Staff

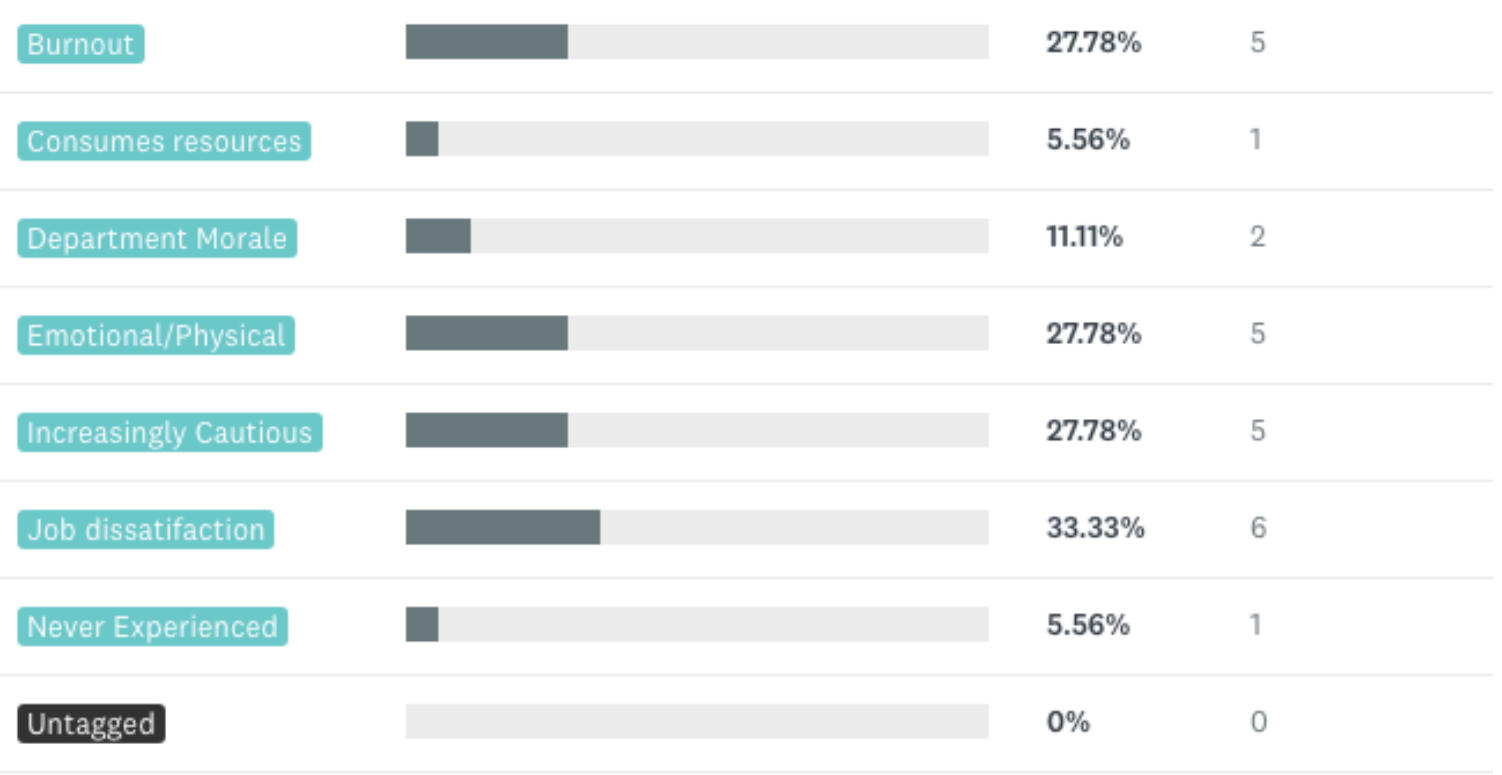


The last open ended question asked for participants to share suggestions to improve in workplace violence in the study site. From this question six themes arose with one response that was unable to be categorized. Education, equipment, management support, security, staff debriefing, and training were the six theme that were identified by respondents. An overwhelming majority of the responses at $66.67 \%(n=10)$ identified the need for more security and the next most reported theme was training for staff at $46.67 \%$ $(n=7)$. The uncategorized respondent accounted for $6.67 \%(n=1)$. Again in some cases, more than one theme was identified by the same participant so the graph depicts more responses than the original sample participants.

Figure 4. Suggestions for Improvement in Workplace Violence.

\begin{tabular}{|l|cc}
\hline Education & $26.67 \%$ & 4 \\
\hline Equipment & $13.33 \%$ & 2 \\
\hline Management support & $26.67 \%$ & 4 \\
\hline Security & $-66.67 \%$ & 10 \\
\hline Staff Debriefing & $-6.67 \%$ & 1 \\
\hline Training & $46.67 \%$ & 7 \\
\hline Untagged & $6.67 \%$ & 1 \\
\hline
\end{tabular}




\section{Summary and Conclusions}

The escalating incidence of workplace violence is affecting healthcare workers from various disciplines and placing them at a greater risk for harm. The Emergency Department has been consistently documented as one area where workplace violence is most prevalent and presents a greater risk for occupational hazard. The escalating acts of violence toward the emergency department nurses across the country have drastically increased and nurses have become targets of verbal and emotional abuse, subjected to threatening behavior, and have become victims of physical assaults. Over $70 \%$ of emergency department nurses reported physical or verbal assault by patients or visitors while they were providing patient care in the emergency setting (Wolf et al.2014). The effects of workplace violence have been documented as burnout, low department morale, physical and emotional distress, and have contributed to overall job dissatisfaction. In addition to the immediate concern for personal safety, workplace violence may significantly decrease emergency department staff productivity and job satisfaction, contributing to loss of work days and to early burnout (Kowalenko et al, 2012). Personal or vicarious experience of aggression or violence in the workplace leads to serious consequences for health professionals, patients, patient care, and organizations (Edward, Ousey, Warelow, \&Lui, 2014,).

The purpose of this project was to identify the effects of workplace violence on nurses working in the Emergency Department at Newport Hospital. To obtain this information a modified version of the ENA Workplace Violence staff assessment survey was emailed to 36 Emergency Department staff nurses in a small community hospital. 
The one-time informational email included an introduction to the project and a link to Survey Monkey.

Participants were asked to answer questions related to their own personal experiences with workplace violence within the emergency department. The survey included a 16 questions total which contained demographic information and a checklist of behaviors related to workplace violence. Participants were asked to denote whether they believe these behaviors to constitute acts of workplace violence and identify if they have experienced them. In addition, two of those questions within the survey were open ended questions aimed to elicit personal accounts of violence in the workplace. If they chose to participate the staff had two weeks to complete and submit the online survey.

Reviewing the results, it was it was found that a majority of the participants identified that most of the behaviors listed constituted workplace violence. Of the thirtysix staff nurses twenty-two completed the survey for overall response rate of $61.1 \%$ and the gender analysis for the study included 3 males $(13.04 \%)$ and 19 females $(86.36 \%)$. Of the twenty-two respondents $50 \%(n=11)$ had 10 years or more of professional nursing experience. In reviewed at least $50 \%$ of the participants can attest to having experience some form of workplace violence and $31.82 \%$ report having experience workplace violence within this past year. Also it was identified that participants reported a higher incidence of non physical violence which consisted of being called names, sworn/cursed at, verbally intimidated, and being yelled or shouted at. Thirteen $13.64 \%(n=3)$ of the staff did not classify the act of being intentionally voided on or voided at as an act of workplace violence. 
The first of two open ended questions that were included in the survey asked the participants to distinguish "how has workplace violence has affected you" and from this six themes arose which included job dissatisfaction, burnout, consumes resources, department morale, emotional/physical, stress and increasingly cautious. Additionally, participants were asked to identify "suggestions for improving how workplace violence is handled in this particular emergency department" from that question six suggestion were acknowledged which included education, equipment, management support, security, staff debriefing, and training. In response to the question of whether nurses feel that workplace violence is a "part of the job" 59.09\% $(\mathrm{n}=13)$ answered yes. As far as overall safety within this particular department it was reported by $59.09 \%$ of $\operatorname{staff}(n=13)$ that they feel somewhat safe from workplace violence overall in the emergency department. Additionally, the overall consensus regarding the questions has workplace violence increased, decreased, or remained the same and overwhelming majority $72.73 \%(n=16)$ reported that it has increased. The formal reporting of the of workplace violence was not performed by $47.62 \%(n=10)$.

Limitations to the study included convenience sampling and the results are based on self reported information. Some of the information obtained could be inaccurate related to personal accounts with workplace violence and personal biases. Additionally, a majority of the participants were female which could represent gender bias.

After review of the survey information it can be established that the prevalence of workplace violence in the emergency department is an issue for nurses. The acts of violent and non violent assaults on nurses is of significant concern and the stated effects 
of workplace violence is consistent with the reported literature. Additionally, the sense of security from the participants of this survey was generally mediocre.

Next, recommendations and implications will be discussed. 


\section{Recommendations and Implications for the Advanced Practice Nurse}

For this emergency department, it can be inferred that additional services to staff members to better prepare, deal with, and overcome the effects of workplace violence in this department would be beneficial. The staff responses to the open ended questions from the survey highlight some of the effects that workplace violence has on its staff members. There was a direct correlation in this study between job dissatisfaction, low morale, emotional/physical stress, and burnout. Staff members identified education, training, security, equipment, staff debriefing, and management support as ways of improving how workplace violence is handled. The prevalence of workplace violence is prominent in the healthcare setting.

The Advanced Practice Registered Nurse (APRN) can assist in identifying evidence based practice procedures which can be incorporated into healthcare systems to reduce the frequency of workplace violence, improve security, and provide support to all emergency department staff to overcome this growing occupational hazard. Through education and training the APRN can serve as an educator and advocate for staff members providing them with essential techniques to be better prepared to handle violence within the workplace. One of the key components in prevention of work place violence is to educate nurses to identify risk factors for violence and provide safety tips for dealing with violent situations. This education can be incorporated into monthly unit council meetings, professional practice committees, and yearly department competency training. 
The APRN can effectively implement change by being actively involved in leadership roles within the hospital setting, community, state, and legislative levels providing education, advocacy, and awareness of mounting issue.

Advocating for stricter laws, enforced policies, training, and support of healthcare organizations on reporting incidences within the workplace are are needed in place to protect nurses from the various forms of violence in the workplace and to provide them with a safe and adequate working environment.

\section{Dissemination Plan}

The results of this project was shared with the $\mathrm{CNO}$ and Director of the Emergency Department at Newport Hospital and Emergency Department staff at the monthly unit council meeting. The project will be presented at the Rhode Island College Master Project presentations in May 2018. 


\section{References}

Arnetz, J. E., Hamblin, L., Essenmacher, L., Upfal, M. J., Ager, J., \& Luborsky, M. (2015). Understanding patient-to-worker violence in hospitals: a qualitative analysis of documented incident reports. Journal Of Advanced Nursing, 71(2), 338-348. doi:10.1111/jan.12494

Catlette, M. (2005). A descriptive study of the perceptions of workplace violence and safety strategies of nurses working in level I trauma centers. Journal of Emergency Nursing, 31(6), 519-525.

Campbell, J.C, Messing, J., Kub, J., Angew, J., Fitzgerald, S., Fowler, B., Sheridan, D., Lindauer, C., Deaton, J., Bolyard, R., (2011). Workplace violence prevalence and risk factors in the safe at work study. Journal of Occupational and Environmental Medicine, 53, 82-87.

Center for Disease Control and Prevention. The National Institute for Occupational Safety and Health (2016). Occupational Violence. Retrieved from https://www.cdc.gov/niosh/topics/violence/default.html

Crisis Prevention Institute. (2017). About CPI. Retrieved from https://www.crisisprevention.com/About-CPI

DiMartino, V. (2002). Framework guidelines for addressing workplace violence in the healthcare sector. Retrieved from http://apps.who.int/iris/bitstream/10665/42617/1/9221134466.pdf

Edward, K.L., Ousey, K., Warelow, P. and Lui, S. (2014) Nursing and Aggression in the Workplace:A Systematic Review. British Journal of Nursing, 23,12, 653-659.

Emergency Nurses Association (2010). ENA Toolkit Workplace Violence. 
Retrieved from http://scratch.ena.f648.net/practice

research/Practice/ToolKits/ViolenceToolKit/Documents/toolkitpg1.htm

Erikson, L., \& Williams-Evans, S. A. (2000, June). Attitudes of emergency nurses regarding patient assaults. Journal of Emergency Nursing, 26, 210-215.

Gacki-Smith, J., Juarez, A. M., \& Boyett, L., Homeyer, C., Robinson, L., \& Maclean, S. (2009). Violence against nurses working in US emergency departments. Journal of Nursing Administration, 39, 340-349.

Gerberich, G., Church, T., McGovern, P., Hansen, H., Nachreiner, N., Gessier, M., ..., Jurek, A. (2005). Risk factors for work related assaults on nurses. Epidemiology, 16(5), 704-709.

Gillespie, L., Gates, D., Berry, P., (2013). Stressful incidents of physical violence against emergency nurses. The Online Journal of Issues in Nursing, 18, 1.

Hahn, S., Hantikainen, V., Needham, I., Kok, G., Dassen, T., \& Halfens, R. J. (2012). Patient and visitor violence in the general hospital, occurrence, staff interventions and consequences: a cross-sectional survey. Journal Of Advanced Nursing, 68(12), 2685-2699. doi:10.1111/j.1365-2648.2012.05967.x

Kowalenko, T., Cunningham, R., Sachs, C., Gore, R., Barat, I., Gates, D.,... Hargarten, S. (2012). Workplace Violence in Emergency Medicine: Current Knowledge and Future Directions. Journal of Emergency Medicine, Volume 43, Issue 3,523 $-531$

OSHA national news release. (2015). OSHA updates guidance for protecting healthcare and social service workers from workplace violence. Retrieved from https://www.osha.gov/news/newsreleases/national/04022015. 
OSHA. (2016). Workplace Violence. Retrieved from https://www.osha.gov/SLTC/workplaceviolence/

Healthy people 2020.gov. Occupational Safety and Health. Healthy People 2020. (2016, September). Retrieved from https://www.healthypeople.gov/2020/topicsobjectives/topic/occupational-safety-and-health

Ray, Melinda M., (July, 2007). The Dark Side of the Job: Violence in the Emergency Department. Journal of Emergency Nursing, 33(3), 257-261

Taylor, Shelley, (1983) Adjustment to threatening events a theory of cognitive adaptation. American Psychologist. 38 (11), 1161-1173

Wolf, L., Delao, A., \& Perhats, C. (2014) Nothing changes, nobody cares: understanding the experience of emergency nurses physically or verbally assaulted while providing care. Journal of Emergency Nursing, 40, 305-309

Zhang, L., Wang, A., Xie, X., Zhou, Y., Li, J., Yang, L., Zhang, J. (2017). Workplace violence against nurses: A cross sectional study. International Journal of Nursing Studies, 72, 8-14. 


\section{Appendix A}

\section{Newport Hospital \\ Lifespan. Delitering health with care"}

August 21, 2017

To Whom It May Concern:

I fully support Alicia Blythe conducting a survey on workplace violence in the Newport Emergency Department for her major project towards her Master's Degree.

Feel free to contact me for any questions

Respectfully,

Lisa Lima-Tessier, MS, RN

Director of Emergency Services

(401) 845-1205 


\section{Appendix B}

\section{Newport Hospital \\ Lifespan. Delivering health with care"}

Newport Hospital

11 Friendship Street

Newport, RI 02840

February 12, 2018

To Whom It May Concern:

Alicia Blythe, RN will be conducting a research project in the emergency department at Newport Hospital titled "The Effects of Workplace Violence on Nursing Working in the Emergency Department". All elements of the research project protocols and policy for Lifepsan will be followed.

I am aware of this research project and I approve it to be carried out in the emergency department at Newport Hospital.

Sincerely,

Orla Brandos, DNP, MBA, MSN, RN, CPHQ, NEA-BC

Vice President, Patient Care Services

\& Chief Nursing Officer 


\section{Appendix C}

To ED Nurses at Newport Hospital,

We would like you to take part in a research study called Workplace Violence. The purpose of the study is to measure the effects of workplace violence on nurses working in the emergency department.

If you choose to participate, you will be asked to complete a survey electronically. The survey will take about 15 minutes of your time. There are 15 questions we would like you to answer by checking the boxes provided that best fit your experiences. In addition, the last two questions ask that you provide a response. This questionnaire is the only thing we will ask of you.

Taking part in this research questionnaire is voluntary and the survey is completely anonymous. The responses to the questions from this study will be kept confidential. None of the information you provided will have your name, any number, or email on it that would identify you personally. The information will be de-identified and reviewed by only the researcher, Alicia Blythe. If you choose to participate in the survey, click on the link provided within the email entitled https://www.surveymonkey.com/r/RXVJK39 Clicking on the link and completing the survey will imply your consent to participate in the study and will direct you to complete the online survey. If you do not want to participate by completing the questionnaire, you are free to choose not to fill out the survey.

If you have any questions or concerns, you can contact me, Alicia Blythe at ablythe 1372@email.ric.edu or 401-741-6340. You may also contact Kathleen Bergeron, the Principal Investigator, at kbergeron@lifespan.org or at 401-316-4382. In addition, if you have any questions about your right as a participant please feel free to contact Janice Muratori at Lifespan Institutional Review Board 401-444-6897. You may also contact the IRB at Rhode Island College at IRB@ric.edu.

Thank you very much for your time.

Kathleen Bergeron MS, APRN (CNS-BC), CEN

Alicia Blythe, RN, BSN 


\section{Appendix D}

Demographic Information:

Gender- Male Female

Primary shift- Days Evenings Nights

Years of Experience 0-5 $5-10$ $10-20$

Employee Status- Fulltime Part-time PerDiem

- Rate how safe you feel from workplace violence in the ED overall as well as in each area of this ED.

\begin{tabular}{|c|c|c|c|c|c|}
\hline & $\begin{array}{c}\text { Not at } \\
\text { all Safe }\end{array}$ & & $\begin{array}{c}\text { Not } \\
\text { Decided }\end{array}$ & & VerySafe \\
\hline $\begin{array}{l}\text { Overall level of } \\
\text { safety in the ED }\end{array}$ & (1) & (2) & (3) & (4) & (5) \\
\hline Triage & (1) & (2) & (3) & (4) & (5) \\
\hline $\begin{array}{l}\text { Exam } \\
\text { (e.g. non-critical } \\
\text { area) }\end{array}$ & (1) & (2) & (3) & (4) & (5) \\
\hline Psychiatric holding & (1) & (2) & (3) & (4) & (5) \\
\hline
\end{tabular}

- Over the past year how many times have you personally experienced workplace violence?
$0-2$ times
3-5 times
6-8 times
9-10 times
$>$ than 10 .

- If you have experienced workplace violence while working at this facility, did you formally report the occurrence(s)?

No, I did not formally report the occurrence(s)

Yes, I formally reported some of the occurrences..... (2)

Yes, I formally reported any occurrence of workplace violence 
- From the actions listed below, indicate which of the following items you believe to constitute workplace violence. Additionally, indicate whether you have personally experienced any of the items.

\begin{tabular}{|c|c|c|c|c|}
\hline \multirow[b]{2}{*}{ Bitten } & \multicolumn{2}{|c|}{$\begin{array}{l}\text { I consider this } \\
\text { action to be } \\
\text { workplace violence }\end{array}$} & \multicolumn{2}{|c|}{$\begin{array}{l}\text { I have personally } \\
\text { experienced this } \\
\text { action while at } \\
\text { work in this ED }\end{array}$} \\
\hline & $\begin{array}{l}\text { Yes } \\
\text { (1) }\end{array}$ & $\begin{array}{l}\text { No } \\
\text { (2) }\end{array}$ & $\begin{array}{l}\text { Yes } \\
\text { (1) }\end{array}$ & $\begin{array}{l}\text { No } \\
(2)\end{array}$ \\
\hline Called names & (1) & (2) & (1) & (2) \\
\hline Hair pulled & (1) & (2) & (1) & (2) \\
\hline $\begin{array}{l}\text { Harassed with sexual } \\
\text { language/innuendo }\end{array}$ & (1) & (2) & (1) & (2) \\
\hline Hit (e.g., punched, slapped) & (1) & (2) & (1) & (2) \\
\hline Hit by thrown objects & (1) & (2) & (1) & (2) \\
\hline Kicked & (1) & (2) & (1) & (2) \\
\hline Pinched & (1) & (2) & (1) & (2) \\
\hline Pushed/shoved & (1) & (2) & (1) & (2) \\
\hline Scratched & (1) & (2) & (1) & (2) \\
\hline Sexually assaulted & (1) & (2) & (1) & (2) \\
\hline Shot/shot at & (1) & (2) & (1) & (2) \\
\hline Spit on/at & (1) & (2) & (1) & (2) \\
\hline Stabbed & (1) & (2) & (1) & (2) \\
\hline Sworn/cursed at & (1) & (2) & (1) & (2) \\
\hline $\begin{array}{l}\text { Threatened with physical } \\
\text { harm }\end{array}$ & (1) & (2) & (1) & (2) \\
\hline Verbally intimidated & (1) & (2) & (1) & (2) \\
\hline
\end{tabular}

- Do you feel that workplace violence from patients and/or visitors is simply a "part of the job" in the ED?

No

Yes 
- Do you feel that workplace violence has increased, remained the same or decreased over the past year?

Increased

Remained the same (2)

Decreased

- How prepared do you feel to manage aggressive or violent behavior?

Not prepared.

Somewhat prepared ... (2)

Prepared

Very Prepared.

Extremely Prepared ... (5)

- How has your experience (s) with workplace violence within your department affected you?

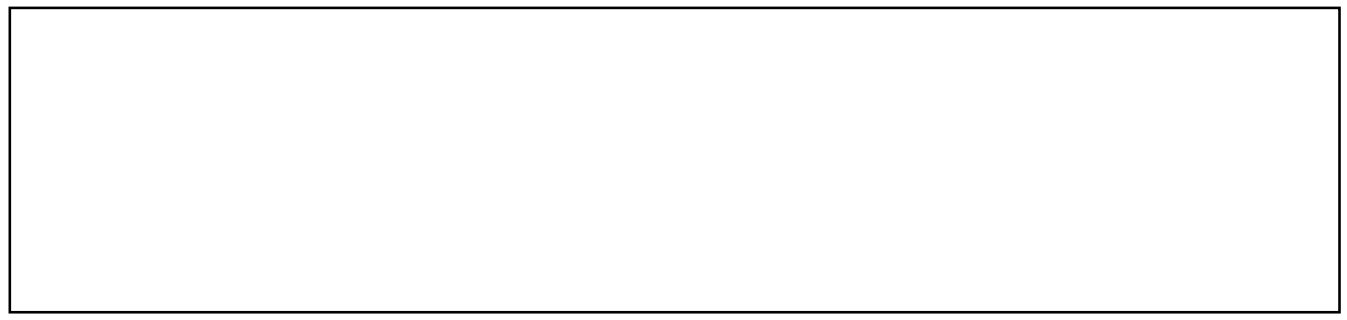

- What suggestions do you have for improving how workplace violence is handled in this emergency department?

(Modified version of the ENA Workplace Violence staff assessment survey) 